\title{
Sperm Preservation: A Review on Current Methods and a Unique Approach
}

\author{
Tsuyoshi Takiuchi ${ }^{1}$, Sora Uematsu ${ }^{2}$, Fumie Saji ${ }^{1}$, Mika Handa ${ }^{1}$, Tsutomu Nishihashi ${ }^{2}$ and Tadashi \\ Kimura $^{1}$ \\ ${ }^{1}$ Department of Obstetrics and Gynecology Graduate School of Medicine, Osaka University, Japan \\ ${ }^{2}$ Graduate school of Engineering, Osaka University, ULVAC-Osaka University Joint Research Laboratory for Future Technology, Japan
}

*Corresponding author: Tsuyoshi Takiuchi, Department of Obstetrics and Gynecology Graduate School of Medicine, Osaka

University, Japan

\begin{tabular}{|c|c|}
\hline ARTICLE INFO & ABSTRACT \\
\hline Received: 㸷 December 05, 2019 & Sperm cryopreservation is a process whereby sperm are generally stored frozen \\
\hline Published: 慧 December 12, 2019 & $\begin{array}{l}\text { at }-196^{\circ} \mathrm{C} \text { in a tank filled with liquid nitrogen (LN2) and a standard practice used in } \\
\text { infertility treatment. However, the LN2 freezing method can be regarded as a fragile }\end{array}$ \\
\hline $\begin{array}{l}\text { Citation: Tsuyoshi Takiuchi, Sora Uematsu, } \\
\text { umie Saji, Mika Handa, Tsutomu Nishi- } \\
\text { ashi, Tadashi Kimura. Sperm Preserva- }\end{array}$ & $\begin{array}{l}\text { storage at room temperature and does not require periodic replenishment of a freezing } \\
\text { agent is necessary. An alternate storage method that is attracting attention is the } \\
\text { lyophilization (freeze-drying) method, although the lyophilization method has not yet } \\
\text { been clinically applied to humans. We introduce a new freeze-drying method (micro- }\end{array}$ \\
\hline
\end{tabular}

Unique Approach. Biomed J Sci \& Tech Res

23(5)-2019. BJSTR. MS.ID.003963.

Keywords: Sperm Preservation; Lyophilization; Micro-Powder-Dry

\section{Introduction}

Sperm cryopreservation is a process whereby sperm are generally stored frozen at $-196^{\circ} \mathrm{C}$ in a tank filled with liquid nitrogen (LN2) after freezing by the LN2 vapor freezing method. It is a standard practice used in infertility treatment, including shortterm storage for artificial insemination and in vitro fertilization, as well as long-term storage before cancer treatment for fertility preservation. In particular, young patients may require long-term storage up to future use thus, there is a need for a stable sperm cryopreservation method.

However, liquid nitrogen is highly volatile; therefore, even if sperm is stored in a special tank, regular replenishment of LN2 is essential. Unfortunately, there have been cases where irreversible loss of stored samples occurred due to insufficient supplementation of LN2 attributed to natural disasters or human errors, and this has become a major social problem. For example, in 2018, a University Hospital in U.S.A. suffered an accident in which about 4000 eggs and embryos were lost following rising temperature caused by failure of the freezer storage and lack of replenishment with LN2
[1]. This example is not a unique case, and similar cases have sporadically occurred in other countries. Such problem arises because regular replenishment of LN2 is indispensable in the LN2 freezing method, which can be regarded as a fragile preservation approach. Therefore, development of an alternative storage method that can permit storage at room temperature and does not require periodic replenishment of a freezing agent is necessary.

\section{Sperm Preservation Methods}

\section{Extracellular Freezing and Intracellular Freezing}

Depending on the rate of freezing, cells freeze via two different ways. When the freezing rate is slow, the water around the cells is first frozen, and the water in the cells move out of the cells to become ice, and then rapidly solidifies at a temperature at which the concentration of solutes in the cells increases. This process is called extracellular freezing, whereby the cell membrane is distorted due to cell volume reduction and the extracellular membrane breaks down the cell membrane [2]. The cell is damaged because it loses 
semi-permeability [3]. In contrast, when the freezing rate is high, the water is frozen inside the cell due to insufficient time for water movement to the outside of the cell. This is called intracellular freezing, and during this process, the cell tissue is destroyed and damaged when coarse ice crystals grow inside the cell [2]. However, cell damage is unlikely to occur if fine ice crystals are generated inside the cell through ultra-rapid cooling [4].

\section{Lyophilization (Freeze-Drying)}

An alternate storage method that is attracting attention is the lyophilization (freeze-drying) method used for long-term storage of foods and pharmaceuticals. In the conventional drying method, liquid water is vaporized into water vapor. In contrast, the lyophilization method, in which ice directly sublimates into vapor without any intermediate liquid phase through freezing followed by depressurizing with a vacuum pump, enables steady maintenance of the concentration of the solution. Thus, cell tissue changes are less likely to occur using this method. However, coarse ice crystals will grow during the longer drying time that follows the cell freezing stage, and cells can become damaged. In addition, if the drying causes excessive dehydration, this may lead to loss of the bound water that helps maintain the tissue structure in the cell, and the cell becomes damaged [3]. Therefore, in order to use the freeze-dry method without damaging the cells, it is necessary to sublimate before ice crystal growth by rapid drying, although this drying should not go beyond the extent where cells become excessively dehydrated. The lyophilization method allows storage of sperm at $4^{\circ} \mathrm{C}$ or room temperature for a long time, does not require regular replenishment of a freezing agent, and is relatively easy to manage. Mouse spermatozoa after freeze-drying can be stored at room temperature for more than one year [5], and can withstand rapid temperature change [6]. In addition, sperm processed by the lyophilization method can withstand storage in space, which is a high radiation environment [7]. These are clearly advantageous in terms of storage stability and convenience compared to conventional methods currently used in reproductive medicine. Although studies using lyophilization methods have been conducted in various animal species including humans, sperm motility after rehydration has not been recovered in all animal species thus far. This is partly because the sperm cell membrane is destroyed [8].

The main causes of the destruction of the cell membrane are likely the ice crystal formation in the solution that occurs during freezing and the pressure and temperature during drying. The current approach to lyophilization of sperm mainly involves the collection of the motile sperm in a lyophilized solution, then freezing in LN2, followed by evaporating the water by vacuum drying in a dry layer [9]. In mice and rabbits, it has been confirmed that fertilizing ability is maintained with freeze-dried sperm [10,11], whereas, there has been no successful application in humans. If motility of sperm is not restored, then pregnancy using artificial insemination or in vitro fertilization, which requires many motile sperm, cannot be achieved. In mice and rabbits, the functions necessary for fertilization and embryo development are maintained even in dead sperm, and intracytoplasmic sperm injection (ICSI) has enabled the use of spermatozoa with disrupted cell membranes. However, in humans, the fertilization rate of ICSI using motionless sperm is extremely low; therefore, the freeze-drying method has not yet been clinically applied to humans. Acquisition of motile sperm after freeze-drying is expected to contribute to the successful reproduction in male cancer patients after long-term treatment, as well as the preservation of rare species. For successful preservation of human sperm, it is therefore necessary to select a method that prevents damage to the sperm cell membrane and suppresses the formation of ice crystals of moisture inside and outside the cell. Here, we introduce a new freeze-drying method that may control the formation of ice crystals in cells.

\section{Micro-Powder-Dry ( $\mu$ PD) Process and Application for Cell Freeze-Drying}

Micro-Powder-Dry ( $\mu$ PD) is a unique freeze-drying process (ULVAC, Inc, Japan Patent P3942093). In the $\mu$ PD process, some liquid containing some ingredients is injected into a vacuum chamber through a nozzle (Figure 1). The liquid jet is dispersed due to its instability and the droplets are frozen rapidly by the evaporation heat (Figure 2). Then, the frozen particles are dried by sublimation in the vacuum chamber and freeze-dried powder can be obtained in the spherical shape (Figure 3). Furthermore, an additional process for rapid drying has been developed, in which the sublimation is accelerated by radiation heat (ULVAC, Inc, patent pending).

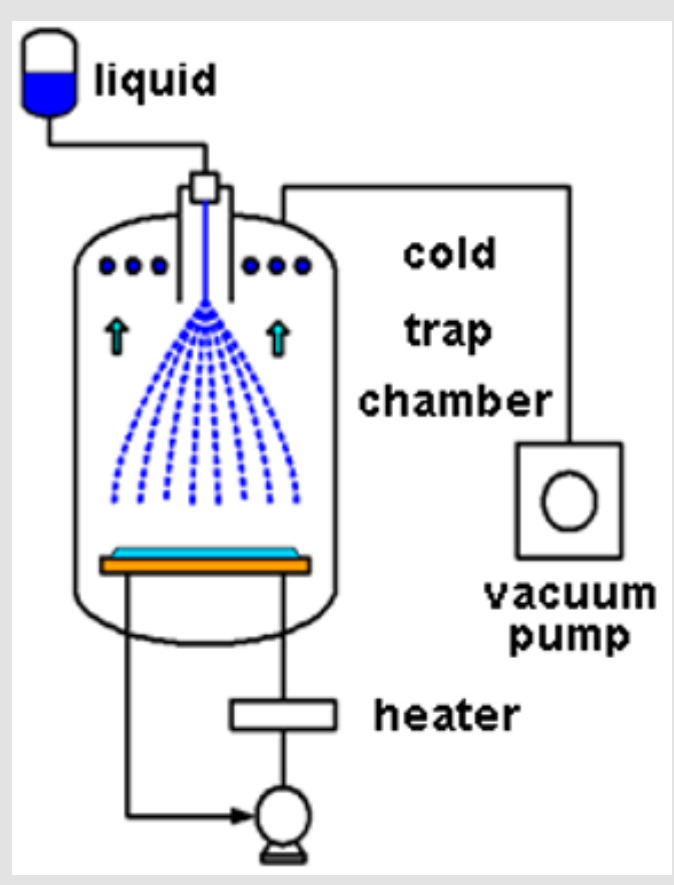

Figure 1: Configuration of Micro-Powder-Dry ( $\mu$ PD). 


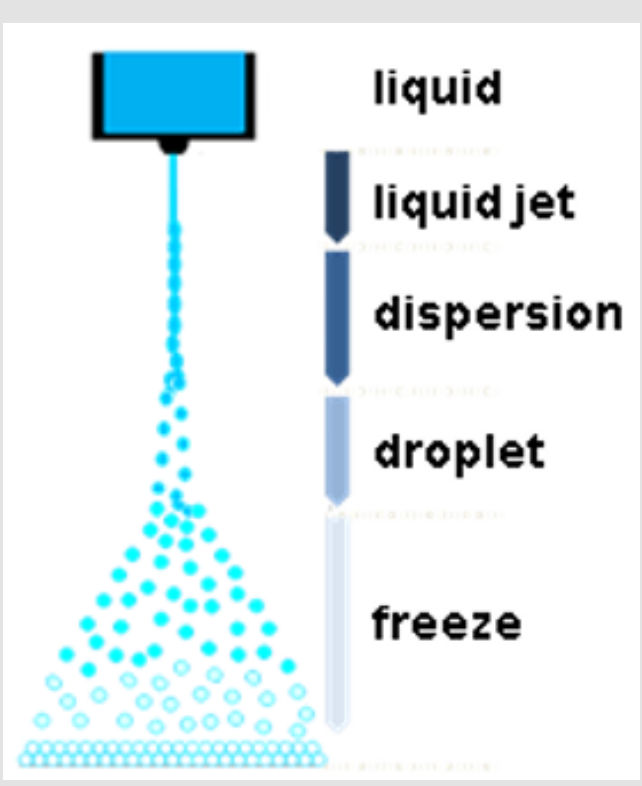

Figure 2: Generation of frozen particles in $\mu \mathrm{PD}$.

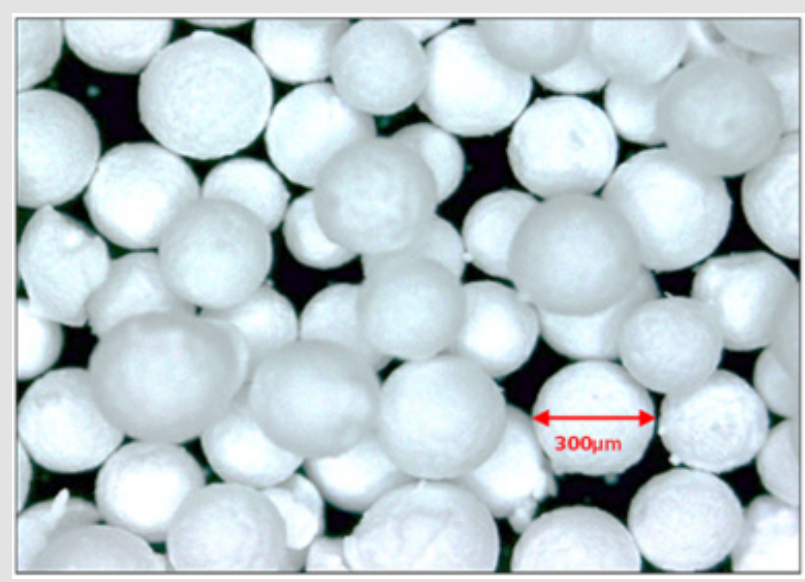

Figure 3: Freeze-dried powder of aqueous mannitol solution $(5 \%)$ using $\mu$ PD.

For freezing cells without damaging cell structures, large intracellular ice crystals should be prevented [12]. Using the $\mu \mathrm{PD}$ process, small ice crystals can be formed due to rapid freezing. In the thermodynamics calculation of a $100 \mu \mathrm{m}$ diameter droplet of pure water, it takes $6 \mathrm{msec}$ for its temperature to fall from 20 to $-35^{\circ} \mathrm{C}$ in a vacuum. Even though small ice crystals are formed, cell structures may be damaged by the grain growth. The rapid drying process using radiation heat could make ice sublimate before the grain growth of ice crystals. In another aspect, aggregation of cells should be prevented for cell freeze-drying. Using the $\mu \mathrm{PD}$ process, the distribution of cells is fixed in micro-droplets when frozen, then ice is sublimated without cell aggregation. For these reasons, $\mu \mathrm{PD}$ is expected to freeze-dry cells with minimal damage. Based on a preliminary experiment, it was found that some freezedried collagenases retained more activity using the $\mu \mathrm{PD}$ process compared to the conventional freeze-dry process. This suggests that $\mu \mathrm{PD}$ could be a better approach for freeze-drying cells and could potentially be applied to the freeze-dried storage of human cells, especially sperm, and this will be examined in future studies.

\section{Conclusion}

The development of an alternative storage method that can permit storage at room temperature and does not require periodic replenishment of a freezing agent is necessary. The lyophilization method will be an alternate storage method, although it has not yet been clinically applied to human sperm, and needs to be improved in order to prevents damage to the sperm cell membrane and suppresses the formation of ice crystals of moisture inside and outside the cell. The $\mu$ PD could be a better approach for freezedrying cells and could potentially be applied to the freeze-dried storage of human sperm, and this will be examined in future studies.

\section{References}

1. (2019) Washington Post: Embryo storage bill seeks oversight of fertility centers and penalties for those that violate safeguards.

2. Hiroshi Souzu (1980) KAGAKU TO SEIBUTSU 18: 78-87.

3. Hiroshi Souzu (1991) Japanese journal of freezing and drying 37: 1-6.

4. Eizo Asahina (1980) journal of freezing and drying 26: 46-51.

5. Kamada Y, Wakayama S, Shibasaki I, Ito D, Kamimura S, et al. (2018) Assessing the tolerance to room temperature and viability of freezedried mice spermatozoa over long-term storage at room temperature under vacuum. Sci Rep 8(1): 10602

6. Wakayama S, Ito D, Kamada Y, Yonemura S, Ooga M etal. (2019) Tolerance of the freeze-dried mouse sperm nucleus to temperatures ranging from $-196^{\circ} \mathrm{C}$ to $150^{\circ} \mathrm{C}$. Sci Rep 9(1): 5719

7. Wakayama S, Kamada Y, Yamanaka K, Kohda T, Suzuki H et al. (2017) Healthy offspring from freeze-dried mouse spermatozoa held on the International Space Station for 9 months. PNAS 114(2): 5988-5993.

8. Kusakabe H, Szczygiel MA, Whittingham DG, Yanagimachi R (2001) Maintenance of genetic integrity in frozen and freeze-dried mouse spermatozoa. PNAS 98(24): 13501-13506.

9. Kaneko $\mathrm{T}$ (2015) Simple sperm preservation by freeze-drying for conserving animal strains. Methods Mol Biol 1239: 317-329.

10. Wakayama T, Yanagimachi R (1998) Development of normal mice from oocytes injected with freeze-dried spermatozoa. Nat Biotechnol 16(7): 639-641.

11. Liu JL, Kusakabe H, Chang CC, Suzuki H, Schmidt DW et al. (2004) Freezedried sperm fertilization leads to full-term development in rabbits. Biol Reprod 70(6): 1776-81.

12. Shimada K, Asahina E (1975) Visualization of intracellular ice crystals formed in very rapidly frozen cells at -27 degree C. Cryobiology 12(3): 209-218. 


\section{ISSN: 2574-1241}

DOI: 10.26717/BJSTR.2019.23.003963

Tsuyoshi Takiuchi. Biomed J Sci \& Tech Res

CC (P) This work is licensed under Creative BY Commons Attribution 4.0 License

Submission Link: https://biomedres.us/submit-manuscript.php

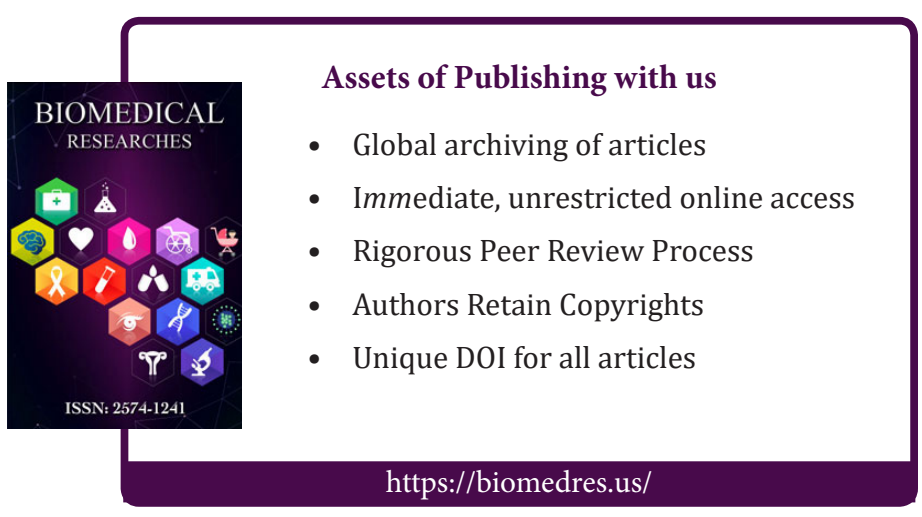

